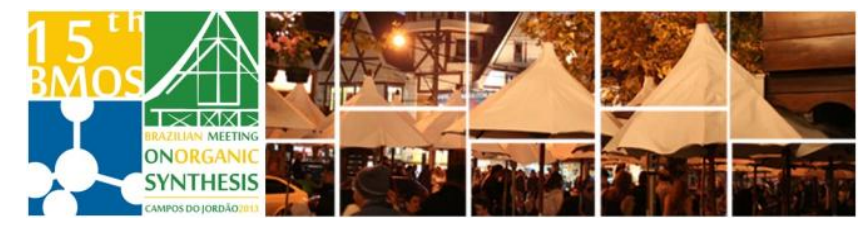

\title{
Synthesis of a new class of 2-bromo-3-amino-1,4- naphthoquinone glycoconjugates
}

\author{
Flaviana Rodrigues Fintelman Dias (PG) ${ }^{\mathrm{a}}$, Vitor Francisco Ferreira (PQ) ${ }^{\mathrm{a}}$, Vinícius \\ Rangel Campos $(P G)^{a}$, Raquel C. Montenegro $(P Q)^{b}$, Maria Cecília B. V. de Souza \\ $(P Q)^{a}$, Anna Claudia Cunha $(P Q)^{\text {a }}$ \\ ${ }^{a}$ Universidade Federal Fluminense, Departamento de Química Orgânica, Programa de Pós-Graduação em \\ Química, Outeiro de São João Batista, 24020-141 Niterói, RJ, Brasil \\ ${ }^{b}$ Universidade Federal do Pará, Instituto de Ciências Biológicas, Belém, PA, Brasil.
}

*corresponding author. Tel.: +55 21 2629-2364; Fax: +55 21 2629-2148; e-mail: annac@vm.uff.br

Keywords: 1,4-naphtoquinone,carbohydrate,antitumor activity

\section{INTRODUCTION}

Bromoquinones have been attracted considerable interest from the scientific community as versatile intermediates in organic synthesis and as antitumor agents ${ }^{1}$. On the other hand, many sugar-containing naphthoquinones ${ }^{2}$ or naphthoquinones having $N$ heterocyclic moiety also have been found to be compounds with antitumor activity.

In this context, we describe the synthesis of a new class of brominated sugar-based naphthoquinone derivatives 1a-c (Scheme 2).

\section{RESULTS AND DISCUSSION}

The synthesis of new aminonaphthoquinone derivatives $\mathbf{2 a - c}$ is shown in the Scheme 1. 5-Amino5-deoxy-1,2-O- isopropylidene- $\beta$-D-ribofuranoside (2a), 6-amino-1,2 :3,4-di-O-isopropylidene- $\alpha$-Dgalactopyranose (2b) and 5-amino-5-deoxy-1,2-Oisopropylidene- $\alpha$-D-xilofuranose (2c) were prepared from their corresponding commercially reagents $D$ ribose, D-xylose, and D-galactose, using the literature methodology of carbohydrate protection and derivatization ${ }^{3}$.

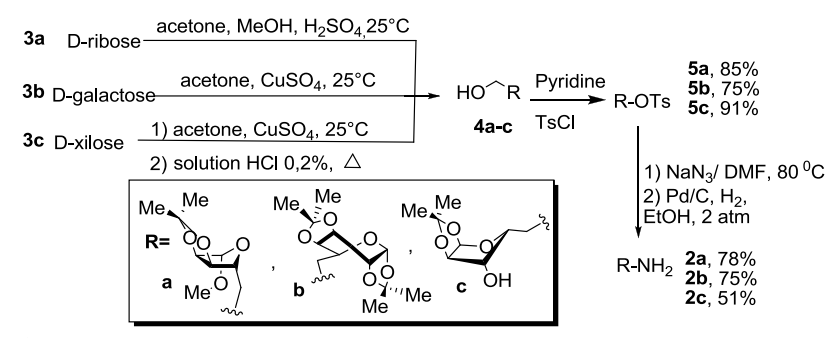

Scheme 1: Preparation of compounds 2a-c.

The ultrasound-accelerated 1,4-addition of aminocarbohydrates 2a-c to 1,4-naphthoquinone (6) was first carried out at room temperature, following the procedure described in the literature. ${ }^{4}$ The reaction of $7 a-c$ with $N$-bromosuccinimide (NBS) led to the corresponding brominated compounds 1a-c in good yields (Scheme 2).

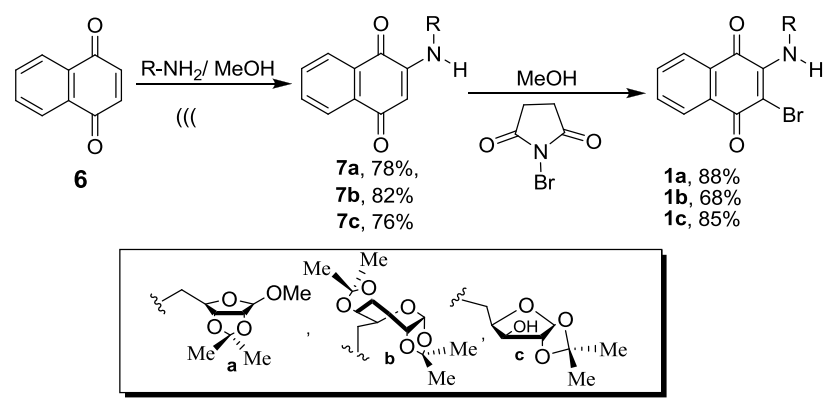

Scheme 2: Synthesis of 2-bromo-1,4aminonaphtoquinone derivatives 1a-c.

\section{CONCLUSION}

The reaction of 1,4-naphtoquinone derivatives $7 \mathbf{a}-\mathbf{c}$ with NBS provided ready access for the construction of brominated sugar-based naphthoquinones in good yields.

Further efforts are being dedicated towards the evaluating of the biological profiles of this novel class of 1,4-naphthoquinones.

\section{ACKNOWLEDGEMENTS}

We thank CNPq-PIBIC, CAPES and FAPERJ for the financial support..

\section{REFERENCES}

${ }^{1}$ Suryavanshi, P. A.; Sridharan, V.; Menéndez, J. C.; Org. Biolmol. Chem. 2010, 8, 3426.

${ }^{2} \mathrm{He}, \mathrm{X}$.; Wang, X.; Jin, X.; Zhou, H.; Shi, X.; Chen, G.; Long, Y.; J. Am. Chem. Soc. 2011, 133, 3649.

${ }^{3}$ Campos, V. R.; Santos, E. A.; Ferreira, V. F.; Montenegro, R. C.; de Souza, M. C. B. V.; Costa-Lotufo, L. V., de Moraes, M. O.; Regufe, A. K. P.; Jordão, A. K.; Pinto, A. C.; Resende, J. A. L. C.; Cunha, A.C. RSC Adv., 2012, 2, 11438.

${ }^{4}$ Franco, C. F. J.; Jordão, A. K.; Ferreira, V. F.; Pinto, A. C.; de Souza, M. C. B. V. ; Resende, J. A. L. C.; Cunha, A. C. J. Braz. Chem., 2010, 22,187. 